\title{
ANALISIS TARIF BERDASARKAN BIAYA OPERASIONAL KENDARAAN (BOK), ABILITY TO PAY (ATP), DAN WILLINGNESS TO PAY (WTP) BUS BATIK SOLO TRANS PADA MASA PANDEMI COVID-19 (STUDI KASUS KORIDOR 1 DAN 2)
}

\author{
Fadila Rahmawati ${ }^{1)}$, Budi Yulianto ${ }^{2)}$, Amirotul Musthofiah H. M. ${ }^{3)}$ \\ 1) Mahasiswa Fakultas Teknik, Prodi Teknik Sipil, Universitas Sebelas Maret \\ 2) \&3) Pengajar Fakultas Teknik, Prodi Teknik Sipil, Universitas Sebelas Maret \\ Jl. Ir. Sutami 36A, Surakarta 57126. Telp.0271-634524. Email : fadila21@student.uns.ac.id
}

\begin{abstract}
Public transportation is one of the mass transportations used as transport many passengers directly to a certain destination. One of the public transportations in the city of Surakarta was the Batik. Solo Trans (BST) bus. For more than a year during the COVID-19 pandemic, various sectors of the country's economic growth experienced a drastic decline. An unstable economy makes transportation costs increase. The purpose of this study was to determine the design of BST fare for corridors 1 and 2 based on the calculation of VOC, ATP, and WTP. Data were obtained from questionnaires distributed to BST passengers. This study uses the Slovin method to determine the number of samples with a value of (e) of $10 \%$. Calculation of Vehicle Operational Costs in this study uses the Ministry of Transportation method and calculates revenue from the plan's load factor of $70 \%$. The data that has been obtained goes to the analysis stage to determine the amount of ATP, WTP, and VOC. Based on the data analysis, it was found that the ATP value of workers was greater than the WTP value of workers. ATP for workers is Rp6.520,96 for corridor 1 and Rp7.139,11 for corridor 2. Meanwhile, the value of WTP for workers is Rp3.735,52 for corridor 1 and Rp3.629,31 for corridor 2. For university students ATP value in corridor 1 is Rp2.752.68 and corridor 2 for Rp2.068,24. This condition is inversely proportional to the WTP value of university students which was Rp3.258,62 for corridor 1 and Rp3.285,71 for corridor 2. The BOK tariff based on the calculation is $\mathrm{R} p 8.965,98$ for corridor 1 and Rp5.823,06 for corridor 2. In general, a new BST fare design is needed university students that is in accordance with their ATP. If the fare design is determined to be above ATP, it can be considered as the amount of subsidies that must be guarantee by the government. As for the workers category, the ATP value is above the WTP value. If service adjustments are made, the ideal fare design will be between the ATP and WTP values.
\end{abstract}

Keywords: Ability to Pay (ATP), Fare Analysis, Vebicle Operational Cost (VOC), Willingness to Pay (WTP)

\begin{abstract}
Abstrak
Angkutan umum adalah alat transportasi massal yang digunakan sebagai sarana perpindahan yang dapat mengangkut banyak penumpang secara langsung ke suatu tujuan. Kota Surakarta memiliki angkutan umum salah satunya yaitu bus Batik Solo Trans (BST). Selama satu tahun lebih berada di masa pandemi COVID-19, berbagai sektor pertumbuhan ekonomi negara mengalami penurunan drastis. Perekonomian yang tidak stabil membuat biaya transportasi meningkat. Tujuan penelitian ini untuk mengetahui desain tarif BST koridor 1 dan 2 berdasarkan perhitungan BOK, ATP, dan WTP. Data didapatkan dari kuesioner yang disebarkan kepada penumpang BST. Penelitian ini menggunakan metode Slovin untuk menentukan jumlah sampel dengan nilai (e) sebesar 10\%. Untuk perhitungan Biaya Operasional Kendaraan menggunakan metode Kementrian Perhubungan dengan load factor rencana sebesar 70\%. Berdasarkan analisis data dan pembahasan dalam penelitian ini didapatkan nilai ATP pekerja lebih besar dari nilai WTP pekerja. ATP pekerja yaitu sebesar Rp6.520,96 untuk koridor 1 dan Rp7.139,11 untuk koridor 2. Sedangkan untuk nilai WTP pekerja yaitu sebesar Rp3.735,52 untuk koridor 1 dan Rp3.629,31 untuk koridor 2. Untuk nilai ATP mahasiswa pada koridor 1 sebesar Rp2.752,68 dan koridor 2 sebesar Rp2.068,24. Kondisi ini berbanding terbalik dengan nilai WTP mahasiswa yang lebih besar yaitu Rp3.258,62 untuk koridor 1 dan Rp3.285,71 untuk koridor 2. Untuk tarif berdasarkan perhitungan BOK adalah Rp8.965,98 per penumpang/rit untuk koridor 1 dan Rp5.823,06 per penumpang/rit untuk koridor 2. Secara umum pada kategori mahasiswa diperlukan desain tarif BST baru yang sesuai dengan kemampuan membayar. Apabila nilai tarif yang ditentukan lebih besar dari ATP, maka jumlah selisih dapat dijadikan sebagai besaran subsidi yang harus ditanggung oleh pemerintah. Sedangkan untuk kategori pekerja, nilai ATP berada di atas nilai WTP. Desain tarif yang ideal terletak di antara nilai ATP dan WTP untuk penyesuaian pelayanan tarif.
\end{abstract}

Kata Kunci : Ability to Pay (ATP), Analisis Tarif, Biaya Operasional Kendaraan (BOK), Willingness to Pay (WTP) 


\section{PENDAHULUAN}

Pembatasan fasilitas dan alat transportasi belum sepenuhnya menjamin penularan COVID-19 akan berkurang. Pernyataan tersebut merupakan bentuk harapan kepada pemerintah yang tetap dapat menyediakan pelayanan sarana dan prasarana transportasi yang menunjang kebutuhan pokok masyarakat di masa pandemi. Sektor transportasi memiliki peran untuk menjamin keberlangsungan bahan-bahan kebutuhan pokok maupun kebutuhan sektor pendukung lainnya agar siap sedia. Adanya hambatan pada arus pergerakan barang jangka pendek seperti putusnya stok pangan dapat berakibat lebih fatal dibandingkan pandemi itu sendiri dan pada jangka panjang lebih berdampak besar terhadap pertumbuhan ekonomi.

Kebijakan pengaturan sarana dan prasarana transportasi di pandemi COVID-19 juga diterapkan pada bus BST, salah satunya mengurangi kapasitas penumpang. Pada situasi pandemi kapasitas penumpang bus hanya dibatasi maksimal 50\% dari kapasitas total yang ada. Penempatan tempat duduk penumpang juga dibatasi dengan selisih satu kursi duduk setiap penumpang satu dengan lainnya. Penumpang juga wajib menggunakan masker dan mengukur suhu tubuh saat menaiki angkutan umum. Hal ini dilakukan agar masyarakat tetap merasa aman saat mengendarai angkutan umum dan tetap dapat beraktivitas. Perubahan ekonomi yang banyak terjadi di masa pandemi COVID-19 mempengaruhi kenaikan harga komponen pada biaya operasional kendaraan (BOK).

Mengetahui Ability to Pay (ATP) dan Willingness to Pay (WTP) merupakan salah satu metode yang dapat menentukan tarif angkutan umum dalam penelitian kali ini yaitu BST. Apabila daya beli masyarakat untuk membayar angkutan umum BST di masa pandemi ini lebih kecil dari tarif yang nantinya akan berlaku, maka pengguna transportasi angkutan umum relatif memilih menggunakan kendaraan pribadi. Penentuan besaran tarif angkutan umum oleh pemerintah memiliki tujuan agar penyelenggaraan angkutan umum dalam kota terjamin dengan mutu jasa standar keselamatan dan pelayanan. Besaran tarif harus dapat menjembatani kemampuan penumpang selaku konsumen dan biaya yang dikeluarkan oleh pengusaha atau operator angkutan umum. Berangkat dari hal tersebut maka perlu diadakan penelitian tentang kebijakan tarif yang akan berlaku di masa pandemi berdasarkan Biaya Operasional Kendaraan (BOK), Ability to Pay (ATP) dan Willingness to Pay (WTP) masyarakat di masa pandemi COVID-19.

\section{METODE}

Biaya Operasional Kendaraan (BOK) merupakan besaran biaya yang dikeluarkan untuk menghasilkan satu satuan unit produksi jasa angkutan. Penelitian ini menggunakan metode Kementrian Perhubungan sesuai Keputusan Direktur Jenderal Perhubungan Darat Nomor SK.687/AJ.206/DRJD/2002 tentang Pedoman Teknis Penyelenggaraan Angkutan Penumpang Umum di Wilayah Perkotaan dalam Trayek Tetap dan Teratur. Metode ini mengelompokkan biaya struktur perhitungan menjadi biaya langsung dan biaya tidak langsung.

Menurut Tamin (1999), Ability to Pay (ATP) adalah kemampuan seseorang untuk membayar jasa pelayanan yang diterimanya berdasarkan penghasilan yang dianggap ideal. Besaran ATP didapatkan dari pendekatan alokasi biaya yang dikeluarkan untuk transportasi dan juga banyaknya perjalanan yang dilakukan pengguna. Nilai ini menunjukkan seberapa besar masyarakat mampu membayar tarif atau ongkos perjalanan yang dilakukan. Dengan menggunakan metode travel cost individual, maka nilai ATP didapat dengan menggunakan persamaan:

$$
A T P=\frac{I_{c} \times \% \mathrm{TC}}{D}
$$

keterangan:

$$
\begin{array}{ll}
\text { ATP } & =\text { kemampuan membayar pengguna } \\
\text { Ic } & =\text { besaran pendapatan } \\
\% \mathrm{TC} & =\text { persentase travel cost yang dikeluarkan } \\
\mathrm{D} & =\text { frekuensi perjalanan }
\end{array}
$$

Menurut Tamin (1999) Willingness to Pay (WTP) adalah kemauan pengguna jasa untuk mengeluarkan imbalan atas apa yang telah ia terima. Berdasarkan penelitian yang telah dilakukan Christoph Breidert dkk. (2006), WTP 
diklasifikasikan menjadi revealed preference dan stated preference. Untuk penelitian ini nilai WTP diperoleh dari survei secara langsung kepada responden dan didapatkan nilai rata-rata (mean) WTP dengan persamaan:

$$
m W T P=\frac{1}{N} \sum_{i=1} n W T P i
$$

keterangan:

mWTP = rata-rata kemauan membayar

$\mathrm{n} \quad=$ ukuran sampel

WTPi = nilai WTP maksimum responden ke-i

Studi dilaksanakan pada angkutan umum Bus Batik Solo Trans (BST) koridor 1 dan 2 yang beroperasi di Surakarta, Jawa Tengah. Waktu pelaksanaan studi dilakukan pada jam operasional BST hari kerja di masa pandemi COVID19. Dalam situasi pandemi yang tidak menyebabkan adanya kegiatan pembelajaran pada sekolah, maka batasan penelitian ini dilakukan pada pengguna dari masyarakat umum yakni pekerja tetap maupun non tetap dan juga mahasiswa. Sebelum dilakukannya pengumpulan data, terdapat survei pendahuluan. Survei ini dilakukan untuk mengetahui waktu penuh dan senggang penumpang pada hari kerja, mengetahui banyaknya armada yang beroperasi untuk penentuan surveyor, dan kuesioner pendahuluan terkait WTP yang disebarkan kepada responden untuk kemudian diuji kevalidan dan keandalannya. Setelah kuesioner terbukti valid dan andal, pelaksanaan pengumpulan data kemudian dilaksanakan. Jumlah sampel ditentukan menggunakan metode Slovin. Pelaksanaan survei utama dilakukan dengan mewawancarai penumpang yang ada dalam bus. Dari wawancara tersebut diperoleh karakteristik penumpang, data primer diantaranya pendapatan dan persentase biaya yang dikeluarkan untuk transportasi serta kemauan membayar penumpang. Sedangkan data sekunder seperti harga komponen BOK didapatkan dari pihak pengelola BST. Data yang telah terkumpul kemudian dianalisis untuk mendapatkan nilai ATP, WTP, dan BOK. Dari perhitungan diketahui besarnya nilai ATP dan WTP yang dikelompokkan berdasarkan kategori mahasiswa dan pekerja. Data yang didapatkan dari pengelola BST digunakan untuk mengolah perhitungan tarif berdasarkan BOK menggunakan metode dari Kementrian Perhubungan dan menghasilkan besaran tarif per penumpang/rit. Pembahasan dilakukan dengan penampilan diagram nilai tarif yang didapatkan dari analisis data dan tarif yang berlaku sebelumnya. Dari gambar diagram dapat dilakukan pembahasan mengenai desain tarif baru yang akan diberlakukan selanjutnya untuk Bus BST koridor 1 dan 2.

\section{HASIL DAN PEMBAHASAN}

\section{Karakteristik Responden}

Responden yang terlibat dalam penelitian ini didominasi oleh penumpang perempuan, usia responden terbanyak dari kalangan 15-25 tahun, dan sebagian besar bertempat tinggal di Soloraya.

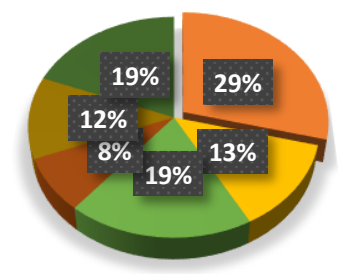

(a)

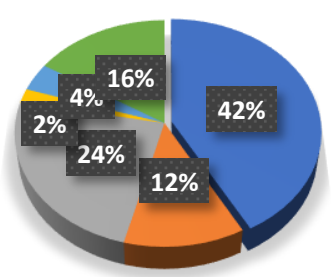

(b)

\author{
- Mahasiswa \\ - Ibu Rumah Tangga \\ - Pegawai Swasta \\ Lain-lain \\ - TNI / Polri / PNS \\ - Wiraswata / Pengusaha
}

Gambar 1. Jenis perkejaan responden (a) koridor 1 dan (b) koridor 2

Dari Gambar 1 dapat ditunjukkan bahwa sebagian besar responden berasal dari kalangan mahasiswa kemudian disusul dengan pekerja dari pegawai swasta. Kategori mahasiswa pada umumnya belum memiliki pekerjaan sehingga pendapatan didapatkan dari uang saku yang diterima selama satu bulan. Maka nilai pendapatan kategori 
mahasiswa dibedakan dengan pekerja yang notabene berpendapatan tetap. Tampilan pendapatan responden dapat dilihat pada Gambar 2 sebagai berikut:

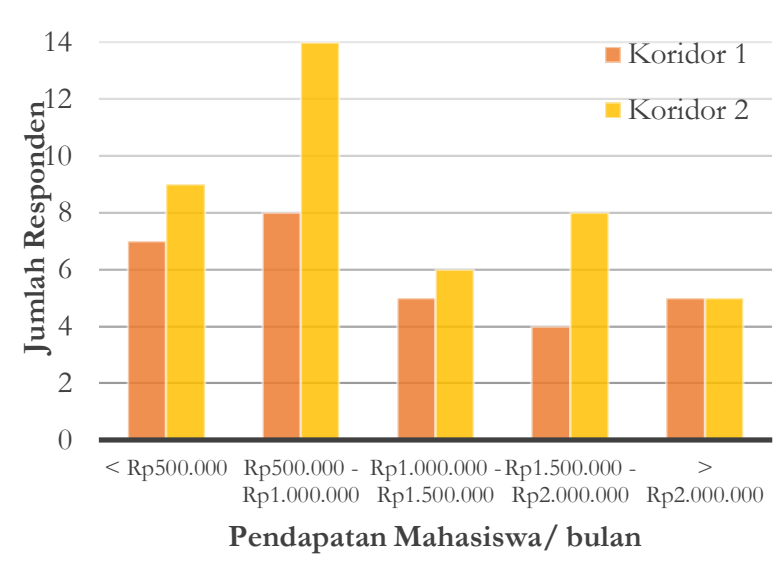

(a)

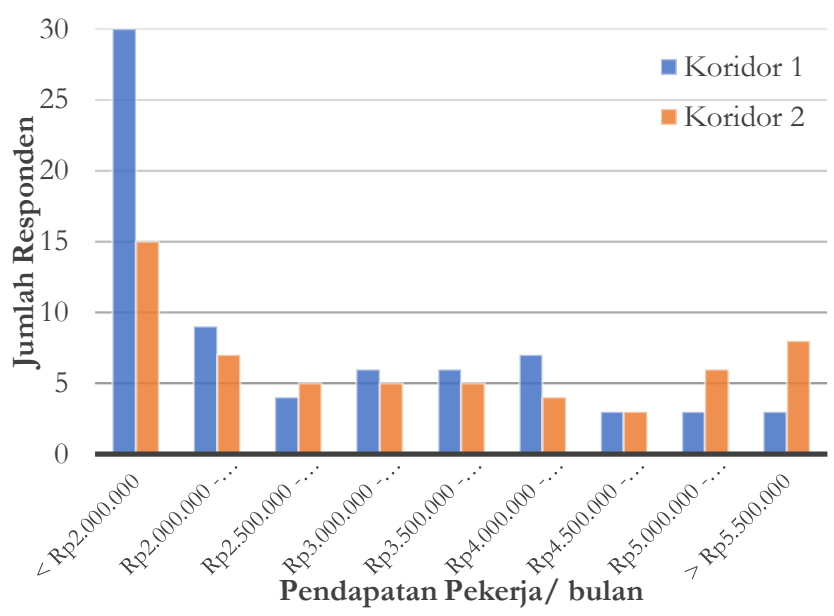

(b)

Gambar 2. Jumlah pendapatan (a) kategori mahasiswa (b) kategori pekerja

Dari Gambar 2 dapat ditunjukkan bahwa sebagian besar responden kategori mahasiswa berpendapatan kurang dari Rp1.000.000,00 dan responden kategori pekerja sebagian besar berpendapatan kurang dari Rp2.000.000,00.

\section{Ability to Pay (ATP)}

a) Kategori Mahasiswa

Penelitian ini mengelompokkan ATP berdasarkan jumlah pendapatan. Sedangkan untuk asumsi frekuensi perjalanan (D) adalah banyaknya perjalanan yang dilakukan responden dari tempat tinggal untuk berangkat dan pulang kuliah dalam satu bulan.

$$
\begin{aligned}
\mathrm{D} & =5 \text { (jumlah hari kuliah) } \times 2 \text { (pulang pergi) } \times 4 \text { (minggu) } \\
& =40
\end{aligned}
$$

Dari hasil survei, didapatkan data jumlah pendapatan mahasiswa. Tiap tingkatan pendapatan tersebut dicari ratarata travel cost sesuai dengan data yang telah didapatkan. Berikut merupakan salah satu data travel cost yang didapat.

\begin{tabular}{|c|c|c|c|c|c|c|}
\hline \multirow[b]{2}{*}{ Pendapatan } & \multicolumn{5}{|c|}{$\%$ Travel Cost } & \multirow{2}{*}{$\begin{array}{c}\text { Rata- } \\
\text { rata }\end{array}$} \\
\hline & $\begin{array}{c}< \\
5 \%\end{array}$ & $5 \%-10 \%$ & $10 \%-15 \%$ & $15 \%-20 \%$ & $>20 \%$ & \\
\hline$<\operatorname{Rp} 500.000$ & 6 & 1 & - & - & - & $5,36 \%$ \\
\hline Rp500.000-Rp1.000.000 & 4 & 4 & - & - & - & $6,25 \%$ \\
\hline Rp1.000.000-Rp1.500.000 & 2 & 2 & 1 & - & - & $7,50 \%$ \\
\hline Rp1.500.000-Rp2.000.000 & 2 & 2 & - & 1 & - & $8,75 \%$ \\
\hline$>\mathrm{Rp} 2.000 .000$ & 1 & 1 & 2 & - & 1 & $11,50 \%$ \\
\hline
\end{tabular}

Tabel 1. Travel cost kategori mahasiswa pada BST Koridor 1

Dari Tabel 1 dapat ditunjukkan bahwa persentase travel cost terbesar merupakan dari kategori mahasiswa dengan pendapatan $>$ Rp2.000.000. Contoh perhitungan kategori mahasiswa pada koridor 1 dengan pendapatan $<$ Rp500.000,00 adalah sebagai berikut:

$$
\begin{aligned}
\text { ATP } & =\frac{\text { Rp500.000,00 × 5,36\% }}{40} \\
& =\text { Rp669,64 }
\end{aligned}
$$

Dari perhitungan yang dilakukan pada tiap tingkatan pendapatan, maka didapatkan nilai rekapitulasi besaran ATP kategori mahasiswa pada koridor 1 dan 2 yang ditampilkan pada Tabel 2 di bawah ini: 
Tabel 2. Rekapitulasi Nilai ATP Mahasiswa pada BST Koridor 1 dan 2

\begin{tabular}{ccc}
\hline Pendapatan & Koridor 1 & KTP \\
\hline$<\mathrm{Rp} 500.000$ & $\mathrm{Rp} 669,64$ & $\mathrm{Rp} 1.319,44$ \\
$\mathrm{Rp} 500.000-\mathrm{Rp} 1.000 .000$ & $\mathrm{Rp} 1.171,88$ & $\mathrm{Rp} 970,98$ \\
$\mathrm{Rp} 1.000 .000-\mathrm{Rp} 1.500 .000$ & $\mathrm{Rp} 2.343,75$ & $\mathrm{Rp} 1.953,13$ \\
$\mathrm{Rp} 1.500 .000-\mathrm{Rp} 2.000 .000$ & $\mathrm{Rp} 3.828,13$ & $\mathrm{Rp} 2.597,66$ \\
$>$ Rp2.000.000 & $\mathrm{Rp} 5.750,00$ & $\mathrm{Rp} 3.500,00$ \\
\hline Rata-rata & $\mathrm{Rp} 2.752,68$ & $\mathrm{Rp} 2.068,24$ \\
\hline
\end{tabular}

Dari Tabel 2 didapatkan nilai ATP Mahasiswa pada koridor 1 meningkat seiring tingginya pendapatan, sedangkan pada koridor 2, lebih tinggi nilai ATP pada pendapatan terendah daripada pendapatan satu tingkat di atasnya.

b) Kategori Pekerja

Penelitian ini mengelompokkan ATP berdasarkan jumlah pendapatan. Sedangkan untuk asumsi frekuensi perjalanan (D) responden adalah banyaknya perjalanan yang dilakukan responden dari tempat tinggal untuk berangkat dan pulang kerja setiap hari dalam satu bulan.

$\mathrm{D}=7$ (jumlah hari kuliah) $\times 2$ (pulang pergi) $\times 4$ (minggu)

$$
=56
$$

Dari data yang didapatkan dan perhitungan yang dilakukan pada tiap tingkatan pendapatan, maka nilai rekapitulasi besaran ATP kategori pekerja pada koridor 1 dan 2 dapat dilihat pada Tabel 3 di bawah ini:

Tabel 3. Rekapitulasi Nilai ATP Pekerja pada BST Koridor 1 dan 2

\begin{tabular}{ccc}
\hline Pendapatan & \multicolumn{2}{c}{ ATP } \\
\hline$<$ Rp2.000.000 & Rp2.559,52 & Rp2.857,14 \\
Rp2.000.000-Rp2.500.000 & Rp3.683,04 & Rp3.874,36 \\
Rp2.500.000-Rp3.000.000 & Rp7.059,15 & Rp5.401,79 \\
Rp3.000.000-Rp3.500.000 & Rp5.319,94 & Rp4.062,50 \\
Rp3.500.000-Rp4.000.000 & Rp5.022,32 & Rp5.691,96 \\
Rp4.000.000-Rp4.500.000 & Rp7.589,29 & Rp8.537,95 \\
Rp4.500.000-Rp5.000.000 & Rp9.895,83 & Rp9.188,99 \\
Rp5.000.000-Rp5.500.000 & Rp9.375,00 & Rp13.281,25 \\
$>$ Rp5.500.000 & Rp8.184,52 & Rp11.356,03 \\
\hline Rata-rata & Rp6.520,96 & Rp7.139,11 \\
\hline
\end{tabular}

Dari Tabel 3 dapat dilihat secara garis besar nilai ATP kategori Pekerja meningkat tiap bertambahnya pendapatan. Berikut merupakan rekapitulasi nilai ATP dari BST koridor 1 dan 2 yang ditunjukkan pada Gambar 3 di bawah ini:

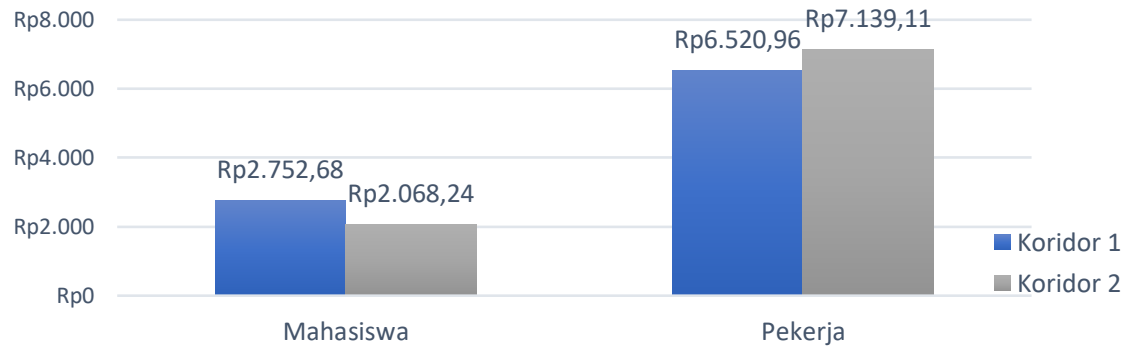

Gambar 3. Rekapitulasi nilai ATP pada BST

Dari Gambar 3 dapat ditunjukkan bahwa nilai ATP kategori Mahasiswa pada kedua koridor masih berada di bawah tarif umum yang berlaku sebelumnya yaitu Rp4.500, sedangkan nilai ATP kategori Pekerja pada kedua koridor berada di atas nilai tarif yang berlaku sebelumnya. Maka disini kategori Pekerja dapat dikatakan mampu untuk membayar jasa angkutan umum Bus BST sesuai tarif yang berlaku sebelumnya 


\section{Willingness to Pay (WTP)}

a) Kategori Mahasiswa

Dari hasil survei, didapatkan tarif yang dipilih mahasiswa. Kemudian pilihan tersebut digolongkan tiap pendapatan dan didapatkan nilai rata-rata WTP. Contoh perhitungan WTP kategori mahasiswa pada koridor 1 adalah:

$$
\begin{aligned}
W T P & =\frac{(R p 3.857,14 \times 7)+(R p 2.812,50 \times 8)+(R p 3.000,00 \times 5)+(R p 3.250,00 \times 4)+(R p 3.400,00 \times 5)}{29} \\
& =\text { Rp3.258,62 }
\end{aligned}
$$

Contoh perhitungan WTP kategori mahasiswa pada koridor 2 adalah:

$$
\begin{aligned}
W T P & =\frac{(R p 3.000,00 \times 9)+(R p 3.285,71 \times 14)+(R p 3.250,00 \times 6)+(R p 3.375,00 \times 8)+(R p 3.700,00 \times 5)}{42} \\
& =\operatorname{Rp} 3.285,71
\end{aligned}
$$

b) Kategori Pekerja

Dari hasil survei, didapatkan tarif yang dipilih pekerja. Kemudian pilihan tersebut digolongkan tiap pendapatan dan didapatkan nilai rata-rata WTP. Contoh perhitungan WTP kategori pekerja pada koridor 1 adalah:

$$
\begin{aligned}
& (R p 3.733,33 \times 30)+(R p 3.777,78 \times 8)+(R p 3.875,00 \times 4)+(R p 3.833,33 \times 6)+(R p 3.750,00 \times 6) \\
W T P= & +(R p 3.625,00 \times 4)+(R p 3.333,33 \times 3)+(R p 3.500,00 \times 6)+(R p 4.125,00 \times 8) \\
= & \text { Rp } 38.735,52
\end{aligned}
$$

Contoh perhitungan WTP kategori pekerja pada koridor 2 adalah:

$$
\begin{aligned}
& \text { WTP }=(\operatorname{Rp} 3.600,00 \times 15)+(\operatorname{Rp} 3.857,14 \times 7)+(\operatorname{Rp} 3.700,00 \times 5)+(\operatorname{Rp} 3.300,00 \times 5)+(\operatorname{Rp} 3.200,00 \times 5) \\
& =\operatorname{Rp} 3.629,31 \\
& (R p 3.600,00 \times 15)+(R p 3.857,14 \times 7)+(R p 3.700,00 \times 5)+(R p 3.300,00 \times 5)+(R p 3.200,00 \times 5)+ \\
& W T P=\frac{(R p 3.625,00 \times 4)+(R p 3.333,33 \times 3)+(R p 3.500,00 \times 6)+(R p 4.125,00 \times 8)}{58} \\
& =\operatorname{Rp} 3.629,31
\end{aligned}
$$

Berikut merupakan rekapitulasi nilai WTP dari BST koridor 1 dan 2 yang ditunjukkan Gambar 4 di bawah ini:

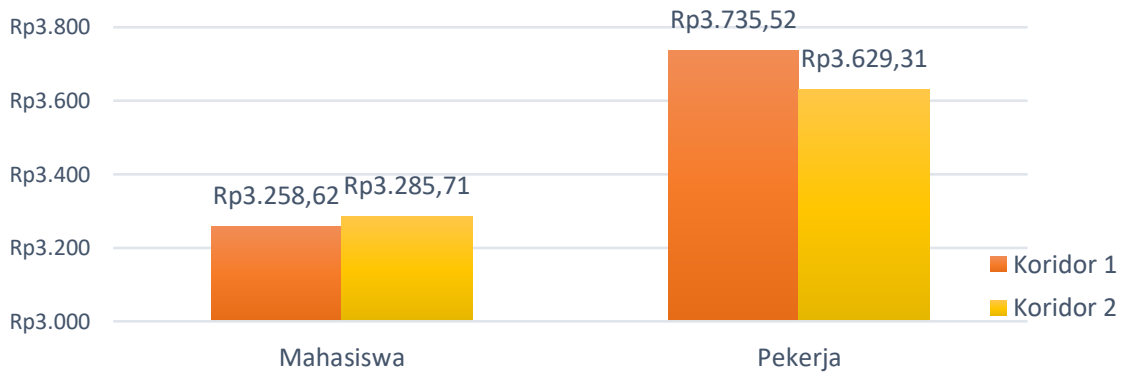

Gambar 4. Rekapitulasi nilai WTP pada BST

Dari Gambar 4 dapat ditunjukkan bahwa nilai WTP pada kedua kategori berada di bawah nilai tarif yang berlaku sebelumnya yaitu Rp4.500,00. 


\section{Biaya Operasional Kendaraan}

Tabel 4. Rekapitulasi Komponen BOK pada BST Koridor 1 dan 2

\begin{tabular}{lll}
\hline Komponen BOK & Koridor $\mathbf{1}$ & Koridor 2 \\
\hline Biaya Langsung & & \\
Biaya Penyusutan & $\mathrm{Rp} 1.142,25$ & $\mathrm{Rp} 853,39$ \\
Biaya Awak Bus & $\mathrm{Rp} 1.083,68$ & $\mathrm{Rp} 1.040,95$ \\
Biaya BBM & $\mathrm{Rp} 1.471,43$ & $\mathrm{Rp} 1.030,00$ \\
Biaya Ban & $\mathrm{Rp} 504,00$ & $\mathrm{Rp} 360,00$ \\
Biaya Pemeliharaan Kendaraan & $\mathrm{Rp} 845,96$ & $\mathrm{Rp} 870,35$ \\
Biaya Terminal & $\mathrm{Rp} 10,66$ & $\mathrm{Rp} 10,24$ \\
Biaya PKB (STNK) & $\mathrm{Rp} 35,70$ & $\mathrm{Rp} 26,67$ \\
Biaya Keur Bus & $\mathrm{Rp} 2,38$ & $\mathrm{Rp} 2,29$ \\
Biaya Asuransi & $\mathrm{Rp} 178,48$ & $\mathrm{Rp} 133,34$ \\
Biaya Asuransi Penumpang & $\mathrm{Rp} 35,82$ & $\mathrm{Rp} 45,16$ \\
Biaya Tidak Langsung & $\mathrm{Rp} 42,48$ & $\mathrm{Rp} 73,56$ \\
\hline Total Biaya per Bus / km & $\mathbf{R p 5 . 3 5 2 , 8 2}$ & $\mathbf{R p 4 . 3 8 2 , 9 5}$ \\
\hline Biaya per penumpang / km & & \\
dengan Load Factor eksisting 70\% & $\mathrm{Rp} 199,57$ & $\mathrm{Rp} 208,71$ \\
\cline { 2 - 3 } Km tempuh per rit & \multicolumn{4}{c}{$47 \mathrm{~km}$} & $30 \mathrm{~km}$ \\
\hline Biaya per penumpang / rit & $\mathbf{R p 8 . 9 6 5 , 9 8}$ & $\mathbf{R p 5 . 8 2 3 , 0 6}$ \\
\hline
\end{tabular}

\section{Pembahasan}

Berdasarkan hasil perhitungan dan analisis yang telah dibahas sebelumnya, maka didapatkan desain tarif seperti yang ditampilkan di bawah ini:

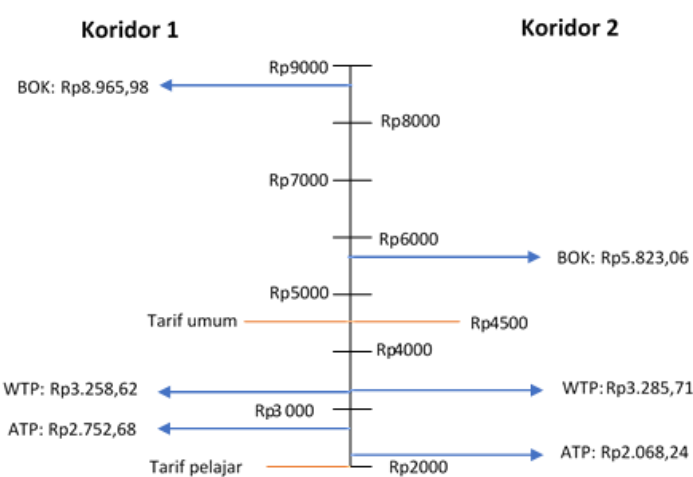

Gambar 5. Diagram desain tarif kategori mahasiswa pada penumpang BST

Dari Gambar 5 menunjukkan bahwa ATP kategori mahasiswa masih berada di bawah tarif yang berlaku sebelumnya. Sedangkan nilai WTP mahasiswa berada di atas nilai ATP. Dari kondisi tersebut diperlukan desain tarif baru yang dinilai ramah untuk mahasiswa yaitu di bawah nilai ATP atau berupa pemberian subsidi dari pemerintah yang dapat meringankan biaya pengeluaran untuk menaiki angkutan umum BST.

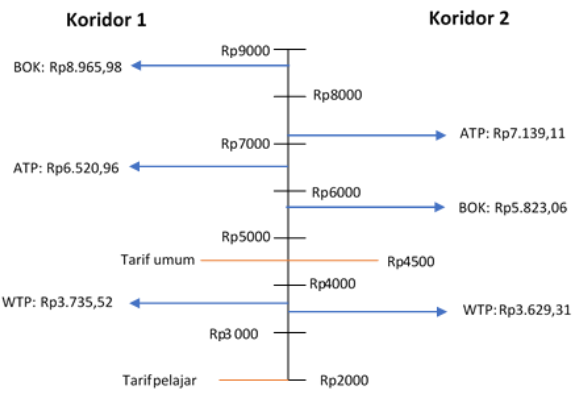

Gambar 6. Diagram desain tarif kategori pekerja pada penumpang BST 
Pada Gambar 6 menunjukkan bahwa nilai ATP pekerja berada di atas nilai WTP dan tarif yang berlaku sebelumnya. Secara keseluruhan dapat dikatakan bahwa pekerja mampu membayar tarif angkutan umum BST. Sedangkan nilai WTP terletak di bawah tarif yang berlaku sebelumnya yang artinya keinginan membayar jasa tersebut rendah. Kondisi ini dapat terjadi apabila penumpang dengan penghasilan relatif tinggi cenderung memiliki pilihan jasa transportasi lain untuk menuju tempat tujuan.

Sedangkan tarif BOK / penumpang - rit secara garis besar berada di atas nilai ATP, nilai WTP, dan tarif yang berlaku sebelumnya. Dengan adanya program Buy the Service yang sedang diterapkan pada BST saat ini, maka pemerintah disini menanggung secara keseluruhan seluruh biaya yang dikeluarkan oleh kendaraan. Apabila nantinya diberlakukan tarif baru, maka besaran selisih terhadap tarif BOK itulah yang harus ditanggung pemerintah sebagai subsidi.

\section{SIMPULAN}

1. Nilai Ability to Pay (ATP) dan Willingness to Pay (WTP) penumpang Bus Batik Solo Trans (BST):

a. Koridor 1

Nilai ATP penumpang pada koridor 1 adalah sebesar Rp2.752,68 untuk kategori mahasiswa dan Rp6.520,96 untuk kategori pekerja. Sedangkan nilai WTP penumpang pada koridor 1 adalah sebesar Rp3.258,62 untuk kategori mahasiswa dan Rp3.735,52 untuk kategori pekerja.

b. Koridor 2

Nilai ATP penumpang pada koridor 2 adalah sebesar Rp2.068,24 untuk kategori mahasiswa dan Rp7.139,11 untuk kategori pekerja. Sedangkan nilai WTP penumpang pada koridor 1 adalah sebesar Rp3.285,71 untuk kategori mahasiswa dan Rp3.629,31 untuk kategori pekerja.

2. Nilai BOK berdasarkan perhitungan metode Kementrian Perhubungan yang didapatkan sebesar Rp8.965,98 per penumpang/rit untuk koridor 1 dan - per penumpang/rit untuk koridor 2.

3. Desain tarif Bus Batik Solo Trans (BST) untuk koridor 1 dan 2 secara umum pada kategori mahasiswa diperlukan desain tarif baru yang sesuai dengan kemampuan membayar. Apabila nilai tarif yang ditentukan lebih besar dari ATP, maka jumlah selisih dapat dijadikan sebagai besaran subsidi yang harus ditanggung oleh pemerintah. Sedangkan untuk kategori pekerja, nilai ATP berada di atas nilai WTP. Desain tarif yang ideal terletak di antara nilai ATP dan WTP untuk penyesuaian pelayanan tarif.

\section{REFERENSI}

Arum, S., \& Samin., 2014, “Analisa Tarif Angkutan Umum Berdasarkan Biaya Operasional Kendaraan, ATP dan WTP”, Jurnal Media Teknik Sipil, Vol 12 No. 2, pp. 183-190. https://doi.org/10.22219/jmts.v12i2.2290

Breidert, C., Hahsler, M., \& Reutterer, T., 2006, "A Review of Methods for Measuring Willingness-to-Pay", Innovative Marketing, pp. 1-32. https://doi.org/10.3111/13696998.2011.644408

Keputusan Direktur Jenderal Perhubungan Darat Nomor SK.687/AJ.206/DPRJD, 2002, "Pedoman Teknis Penyelengaraan Angkutan Penumpang Umum di Wilayah Perkotaan dalam Trayek Tetap dan Teratur". Jakarta

Litman, T., 2003, "Measuring Transportation: Traffic, Mobility and Accessibility', ITE Journal (Institute of Transportation Engineers).

Morlok, E. K., 1998, “Pengantar Teknik dan Perencanaan Transportasi”, Erlangga. Jakarta.

Suryoputro, J., Sumarsono, A., \& Djumari, 2015, “Analisis Tarif Angkutan Umum Berdasarkan Ability to Pay (ATP), Willingness to Pay (WTP) Dan Biaya Operasional Kendaraan (BOK) (Studi Kasus Trans Jogja Rute 4A dan 4B). E-Jurnal Matriks Teknik Sipil, Vol 3 No. 2, pp. 586-592.

Tamin, O.Z., 2000, "Perencanaan dan Pemodelan Transportasi”, Institut Teknologi Bandung. Bandung

Uli B., H. D., 1999, “Analisis Ability to Pay dan Willingness to Pay Tarif Angkutan Kota (Studi Kasus: Kotamadya Medan)", Tesis, Institut Teknologi Bandung. Bandung.

Undang-undang Republik Indonesia No 22 Tahun 2009, 2009, “Lalu Lintas dan Angkutan Jalan”, Jakarta.

Warpani S.P., 2002, 'Pengelolaan Lalu Lintas dan Angkutan Jalan”. Institut Teknologi Bandung. Bandung. 